assumptions and basic equations used, gives graphs of the main quantities tabulated, and also provides some impression of the variability about the tabulated values, which are described as "idealized middle-latitude yoarround mean conditions for the range of solar activity that occurs between sunspot minimum and sunspot maximum".

This rather tortuous phrase indicates at once the main objection to the tables. Is it useful to give just a mean value for, say, air density at $600 \mathrm{~km}$ height, when the density here is known to be over one hundred times greater by day at a strong sunspot maximum than it is by night at sunspot minimum? Anyone who innocently takes the night-time density in 1963 at $700 \mathrm{~km}$ height to be as given by the tables will be in error by a factor of about 20 . No real indication is given of the possible limits of variation at heights above $300 \mathrm{~km}$ : the tables for this region are, it is true, called 'speculative': but that is not a satisfactory description, because the properties are quite well known. The difficulty is to tabulate them adoquately without producing a volume which can only be handled by it weight-lifter. The model atmosphere of Harris and Prietser (National Aeronautics and Space Administration Technical Note D-1444), which tabulates values for each hour of the day and for 5 levels of solar activity, can be recommended to supploment the present volume at heights above $200 \mathrm{~km}$.

The volume is attractively produced, though there are some refinements in detail which would improve it fur ther. For example, there is a useful edge-index page to the main tables; but their titles have unaccountably been printed on the reverse of this page instead of being beside the marks. The tables, which are photographed from a computer 'print-out', and the introductory text appear to be creditably free of misprints, though there is a serious error on Fig. 1. 3.5, where the scale for the mean free path should be metres not kilometres.

If the limitations implied by its mean-value tabulations are borne in mind, the book is an excellent work of reference. D. G. KING-Hele

\section{SCIENCE FOR SCHOOLCHILDREN}

\section{The Atom}

By Charles Hatcher. (Quantum Books, No. 1.) Pp. 108.

\section{Space Around Us}

By Leo Schneider. (Quantum Books, No. 2.) Pp. 104.

\section{Exploring the Universe}

By Leo Schneider. (Quantum Books, No. 3.) Pp. 111. (London: Macmillan and Co., Ltd., 1963.) 15s. each.

$\mathrm{HE}$ publishers of these little books intend that each shall provide a readable introduction to some scientific topic for a child of fourteen years or more. Next spring there are to be three more and others will follow. The books are well produced and well printed; they contain numerous diagrams, generally well devised and clearly drawn, together with a number of good photographs and a fow statistical tables.

The Atom is a most successful exposition in simple terms of the Rutherford-Bohr atom, of simple nuclear disintegrations and the production of trans-uranic elements, of the uses of radioisotopes, and of the modern nuclear reactor. An introductory section about scientific method is followed by a brief outline of the development of atomic theories from Democritus to Dalton. The work of Rutherford, Thomson and their contemporaries is well summarized and it is particularly pleasing to have descriptions of the instruments used and explanations in simple terms of how they work. A Periodic Table is provided, and the connexion between electron shells and chemical properties is clearly expounded. The whole presentation is most lucid and successful, and Mr. Hatcher is to be congratulated on producing a book that will not only appeal to the fourteen-year-old, but will also provide an excellent qualitative introduction to the whole field for a pupil entering a science sixth-form. Indeed the book is worthy of serious attention from teachers who are concerned with the presentation of this material at sixth-form level.

The other two books, considered together, do for the very large what the first does for the very small, dealing respectively with the information we have about the universe and the instruments used for acquiring our knowledge. In Space Around $U s$ we are first given an account of the importance to all living creatures of air and water, and then a review of the lay-out of the solar system and its relation to the stars. The theory of gravitation is explained and related to the movement of a satellite in orbit in terms that should be intelligible to the young reader. We learn about sunspots and comets, the Moon's phases and Saturn's rings--indeed "all the old romance retold exactly in the ancient way". We visit all the planets in turn and from the surface of Mars watch the strange behaviour of its moons. The imaginative child will be delighted by the speculations as to the possible origin of the solar system. Relatively little space is devoted to the stars but a welcome feature is the chapter describing the London Planetarium.

Exploring the Universe tells how the information contained in its predecessor is collected. From the observatory, around which we are conducted by an astronomer, we proceed to an account of the action of lenses and the construction of telescopes. There is some discussion of the nature of light and we are then introduced to the spectrometer and its importance in astronomy. The deduction of stellar velocities from spectra is explained. There follows an interesting account of the progress made in rocket research, with diagrams and drawings of space rockets, space ships and space stations. The problems of weightlessness are mentioned and there is even a painless treatment of the elementary geometric methods of calculating astronomical distances.

The books will be a welcome addition to a school library and can be most warmly commended.

K. W. Lyox

\section{INTERNATIONAL VACUUM}

\section{I Transactions of the Eighth National Vacuum Symposium}

(American Vacuum Society) Combined with the Second International Congress on Vacuum Science and Tochnology (International Organization for Vacuum Science and Technology, October 16-19, Washington, D.C.). Edited by Luther E. Preuss. Vol. 1: Pp. xxiii +669 . Vol. 2. Pp. viii +670-1351. (London and New York: Pergamon Press, 1962.) £15 net per set.

T O keep abreast with the most recent developments in the science, technology and applications of vacuum. it is difficult to recommend any publications superior to those appearing annually as a result of the conferences of the American Vacuum Society. In this respect, the present two volumes are especially useful as they contain much more material than usual (200 papers), becauso in 1961 the Americans, with typical generosity, were host. at their eighth Vacuum Symposium to the second International Vacuum Congress (the first was held at Namur, Belgium, in 1958). At conferences such as this one, it is true that many of the papers are not strictly original, in that much of the same experimental work has been previously reported by the authors in scientific journals. However, the publication of these volumes enables a detailed survey of the latest work to be available which 